\title{
Osteopontin and Integrin $\alpha v \beta 3$ Expression during the Implantation Window in IVF Patients with Elevated Serum Progesterone and Oestradiol Level
}

\author{
Expression von Osteopontin und Integrin $\alpha v \beta 3$ während des Implantations- \\ fensters in IVF-Patientinnen mit erhöhten Progesteron- und Östradiolwerten
}

Authors

Affiliations

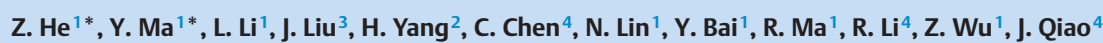

The affiliations are listed at the end of the article.

\author{
Key words \\ - endometrial receptivity \\ - IVF \\ - elevated hormone levels \\ - osteopontin \\ - integrin $\alpha v \beta 3$ \\ Schlüsselwörter \\ - Rezeptivität des \\ Endometriums \\ - IVF \\ - erhöhte Hormonspiegel \\ - Osteopontin \\ - Integrin $\alpha v \beta 3$
}

$\begin{array}{ll}\text { received } & 23.9 .2015 \\ \text { revised } & 20.12 .2015 \\ \text { accepted } & 20.12 .2015\end{array}$

Bibliography

Dol http://dx.doi.org/

10.1055/s-0041-111697

Geburtsh Frauenheilk 2016; 76:

709-717 @ Georg Thieme

Verlag KG Stuttgart · New York .

ISSN 0016-5751

Correspondence
Rong Li, M.D.
Department of Obstetrics
and Gynecology
Reproductive Medical Centre
Peking University Third Hospital
No.49 North Huayuan Road,
Haidian District
Beijing 10091
People's Republic of China
roseli001@sina.com

Ze Wu, Ph.D.

Department of Reproduction and Genetics

Reproductive Medical Centre

The Affiliated Hospital

of Kunming University

of Science and Technology,

The First People's Hospital

of Yunnan Province

No. 157 Jin Bi Road

Kunming 650032

People's Republic of China

wuzes2010@163.com

\section{Abstract \\ $\nabla$}

Background: To explore whether endometrial receptivity is determined by osteopontin (OPN) and integrin $\alpha v \beta 3$ expression in women with elevated serum progesterone $(\mathrm{P})$ and/or oestradiol $\left(\mathrm{E}_{2}\right)$ who are undergoing in vitro fertilisation (IVF).

Methods: According to serum hormone levels on the day of HCG administration, 33 infertile women were divided into 3 groups: the high $\mathrm{E}_{2}$, high $\mathrm{P}$, and high $\mathrm{E}_{2}$ and $\mathrm{P}$ groups. The control group included 11 fertile, healthy women. Endometrial biopsy was performed on ovulation day +7 to +8 for all study participants, and the mRNA and protein expression levels of OPN and integrin $\alpha \mathrm{v} \beta 3$ were analyzed.

Result: No statistically significant differences regarding OPN and integrin $\alpha v \beta 3$ expression were found between infertile patients in the high $\mathrm{P}$, high $\mathrm{E}_{2}$, high $\mathrm{E}_{2}$ and $\mathrm{P}$ and control groups. There was no significant correlation between OPN and integrin $\alpha v \beta 3$ staining intensity during the implantation window biopsy in any of the groups studied.

Conclusion: Endometrial OPN and integrant $\alpha v \beta 3$ expression/co-expression is not impaired during the window of implantation in patients with high $\mathrm{P}$, high $\mathrm{E}_{2}$, or high $\mathrm{E}_{2}$ and $\mathrm{P}$ levels. The clinical value of assessing endometrial receptivity with OPN and integrin $\alpha v \beta 3$ seems to be uncertain.

\section{Zusammenfassung \\ $\nabla$}

Hintergrund: Ziel der Studie war es zu untersuchen, ob die Rezeptivität des Endometriums von der Osteopontin- (OPN-) und Integrin $\alpha v \beta 3$ Expression bestimmt wird bei Frauen mit erhöhten Progesteron-(P-) und/oder Östradiol-( $\left.E_{2^{-}}\right)$ Konzentrationen, die sich einer In-vitro-Fertilisation (IVF) unterziehen.

Methoden: Basierend auf der Messung des Hormonspiegels am Tage der hCG-Gabe wurden 33 unfruchtbare Frauen in 3 Gruppen wie folgt eingeteilt: hoher $\mathrm{E}_{2^{-}}$, hoher $\mathrm{P}$ - und hoher $\mathrm{E}_{2^{-}}$und $\mathrm{P}$ Spiegel. Die Kontrollgruppe bestand aus 11 gesunden fruchtbaren Frauen. Eine Biopsie des Endometriums wurde am 7. oder 8. Tag nach der Ovulation bei allen Studienteilnehmende durchgeführt, und die mRNA und Protein-Expressionsspiegeln von OPN und Integrin $\alpha v \beta 3$ wurden ausgewertet.

Ergebnisse: Bezüglich der Exprimierung von OPN und Integrin $\alpha v \beta 3$ fanden sich keine statistisch signifikanten Unterschiede zwischen den unfruchtbaren Patientinnen in den Gruppen mit hohen P- oder $\mathrm{E}_{2}$-Spiegeln, der Gruppe mit hohen $E_{2^{-}}$und P-Spiegeln und der Kontrollgruppe. In den entnommenen Biopsaten konnte bei keiner der untersuchten Gruppen eine signifikante Korrelation zwischen der Färbungsintensität für OPN und Integrin $\alpha v \beta 3$ und dem Implantationsfenster festgestellt werden.

Schlussfolgerungen: Die Expression und Koexpression von OPN und Integrin $\alpha v \beta 3$ im Endometrium sind während des Implantationsfensters nicht beeinträchtigt bei Patientinnen mit hohen P- oder $\mathrm{E}_{2}$-Spiegeln bzw. hohen $\mathrm{E}_{2}$ - und P-Spiegeln. Der klinische Nutzen einer auf die Messung der Expression von OPN- und Integrin $\alpha v \beta 3$ basierenden Bewertung der Rezeptivität des Endometriums scheint fraglich zu sein.

\footnotetext{
* Co-author: Zhenlin He and Yanping Ma are joint first authors of this article.
} 


\section{Introduction}

$\nabla$

Successful embryo implantation requires a receptive endometrium, while the ovaries provide the hormonal stimulus for establishment of a successful pregnancy [1]. During in vitro fertilization (IVF) cycle, endometrium and embryo are exposed to supra-physiological concentrations of oestradiol $\left(E_{2}\right)$ and progesterone $(\mathrm{P})$ under ovarian stimulation, which could influence pregnancy outcome. Detection of elevated serum $P$ on the day of human chorionic gonadotropin (HCG) administration has been reported to occur in $20-40 \%$ of IVF and embryo transfer (ET) cycles [2]. Moreover, many studies have described an adverse relationship between elevated P concentration on the day of HCG administration and IVF pregnancy outcome [3]. In addition, a negative association between the probability of pregnancy and $\mathrm{E}_{2}$ concentration on the day of HCG administration has also been reported [4]. However, the potential effect of these subtle hormone increases in implantation remains controversial. A more recent publication by the current study group [5] demonstrated that elevated $P$ was detrimental to pregnancy rate, while high serum $E_{2}$ concentration at the time of HCG administration had no effect on IVF pregnancy outcome. A high $\mathrm{E}_{2}$ concentration, combined with elevated $\mathrm{P}$, had the potential negative effect and higher ectopic pregnancy rate. In these prior studies, the theory of reduced endometrial receptivity with high $\mathrm{P}$ concentration was supported in the fresh embryo-transfer cycle.

Endometrial receptivity has been extensively studied, and a number of architectural, cellular, biochemical, and molecular events occurred in the endometrium within the implantation window (i.e. 6-8 days after ovulation) [6]. In particular, integrin $\alpha v \beta 3$ and its extracellular matrix ligand, osteopontin (OPN), are two of the best characterised endometrial receptivity biomarkers. OPN is the main ligand for integrin $\alpha v \beta 3$, and several studies have identified OPN as a putative biomarker for uterine receptivity in human endometrium [7]. Moreover, OPN and integrin $\alpha \mathrm{v} \beta 3$ have been found to be simultaneously expressed in the human endometrium throughout the menstrual cycle in normally cycling fertile women, with both glycoproteins being maximally expressed during the implantation window [8]. The maximal expression of these two molecules during the implantation window in human endometrial epithelial cells and the secretion of OPN into the uterine cavity suggest that these factors play a role in the regulation of endometrial function and embryo implantation $[8,9]$. Detection of both integrin $\alpha v \beta 3$ and OPN has been proposed as means of distinguishing receptive from non-receptive endometria in clinical practice and as a new method to investigate impaired endometrial receptivity in a certain group of infertile patients [10-12].

Different studies have reported that integrin $\alpha v \beta 3$ is not expressed in the endometria of women with certain conditions, such as endometriosis, hydrosalpinges, polycystic ovary syndrome (PCOS), and unexplained infertility [8,13-16]. Recently, Casals et al. [17] studied the expression of OPN and integrin $\alpha v \beta 3$ in seven groups of women who received either CC, ovarian stimulation for IVF, oral contraception, dehydrogesterone for endometrial luteal phase defect, two different regimens of hormone replacement therapy, or no treatment. There were no significant differences between spontaneous and treatment cycles in the seven experimental groups with respect to the expression of OPN and integrin $\alpha v \beta 3$. However, there have been limited studies on IVF cycle, and more prospective clinical controlled studies are needed to investigate these receptivity markers. To our knowledge, there have been no previous controlled investigations on the expression of these two endometrial receptivity markers in IVF patients with elevated $\mathrm{P}$ and/or $\mathrm{E}_{2}$ level in the same cycle. Therefore, it is currently unknown whether elevated levels of $P, E_{2}$, or both $P$ and $E_{2}$ detected on the day of HCG administration influence the expression of OPN and integrin $\alpha v \beta 3$ during the implantation window. Accordingly, the mechanisms underlying impaired implantation in IVF patients with high levels of $\mathrm{P}$ and/or $\mathrm{E}_{2}$ require further exploration. Thus, the aim of the present study was to investigate the endometrial expression and co-expression of OPN and integrin $\alpha v \beta 3$ in infertile women with high sex hormone levels during IVF cycle.

\section{Materials and Methods \\ $\nabla$}

\section{Patients and study design}

All participants underwent a timed endometrial biopsy at the Reproductive Medical Center of the Affiliated Hospital of Kunming University of Science and Technology. The inclusion criteria were as following: women < 38 years of age, no previous diagnosis of adnexal masses, basal serum follicle-stimulation hormone (FSH) on day $2<10 \mathrm{IU} / \mathrm{L}$, regular menstruation, and no hormone treatment during the previous 3 months; all enrolled patients were unable to conceive due to tubal obstruction or male infertility. In this prospective study, patients with endocrinopathies, organic diseases, and other factors affecting endometrial receptivity, such as PCOS, ovarian tumor, polyps, fibroids, endometriosis, and hydrosalpinges, were excluded. Enrolled patients underwent IVFET with a gonadotropin-releasing hormone agonist and recombinant FSH; moreover, in hopes of improving the chance for success during frozen ET cycle, fresh ET for all patients was cancelled to avoid ovarian hyperstimulation syndrome (OHSS) or extraordinary high P level (serum P levels $\geq 2.1 \mathrm{ng} / \mathrm{ml}$, twice the threshold of an elevated P concentration \{i.e., $1.05 \mathrm{ng} / \mathrm{ml}$ on the day of HCG administration, as defined by our previous clinical research [5]\}). According to our previous study [5], a serum P concentration $\geq 1.05 \mathrm{ng} / \mathrm{ml}$ on the day of HCG administration was defined as an elevated $P$ concentration, and $E_{2}$ elevation was defined as a serum $\mathrm{E}_{2}$ concentration exceeding $5210.9 \mathrm{ng} / \mathrm{ml}$. Patients were divided into 3 groups according to their serum $\mathrm{P}$ and $\mathrm{E}_{2}$ concentrations on the day of HCG administration: the high $\mathrm{E}_{2}$ group $\left(E_{2} \geq 5210.9 \mathrm{pg} / \mathrm{ml}\right.$ and $\left.\mathrm{P}<1.05 \mathrm{ng} / \mathrm{ml}\right)$, the high $\mathrm{P}$ group $\left(E_{2}<5210.9 \mathrm{pg} / \mathrm{ml}\right.$ and $\left.\mathrm{P} \geq 1.05 \mathrm{ng} / \mathrm{ml}\right)$, and the high $\mathrm{E}_{2}$ and $\mathrm{P}$ group $\left(E_{2} \geq 5210.9 \mathrm{pg} / \mathrm{ml}\right.$ and $P \geq 1.05 \mathrm{ng} / \mathrm{ml}$ ). Each group included 11 infertile women; the sample size was decided arbitrarily, but in keeping with previous studies on the subject [17-18]. For the specific purpose of this study, the luteal phase was supported with micronized vaginal progesterone soft capsules (TROGESTAN, $100 \mathrm{mg}$ per capsule; Besins Manufacturing Belgium, Capsugel, France), given $400 \mathrm{mg} /$ day for 12 days and commenced on the day of oocyte retrieval.

We also included a control group of 11 fertile healthy women (mean parity 1.3; range 1-2), who were undergoing tubal sterilization and had no history of miscarriage. All of the women had regular menstrual cycle (every 27-32 days) without steroid treatment or other medication for at least 3 months prior to endometrium collection. Endometrial biopsy was performed on ovulation day +7 to +8 for all study participants. Transvaginal ultrasonography (PHILIPS HD5; Philips Co., Holland) was performed to monitor follicular growth beginning from day 8-10 of the natural cycle until follicles disappear. For all patients, the 
largest diameter was measured in both the longitudinal and transverse dimensions in all follicles. The day of ovulation was designated as the day of maximum follicular enlargement, which was followed by sudden disappearance of this follicle and its loss of clear wall demarcation and intrafollicular echoes on the next day $[19,20]$. The chronological day of each patient was determined by counting forward from the ovulation day, as detected by ultrasonographic scan.

For all women, luteal serum concentrations of $E_{2}$ and $P$ and endometrial biopsies were obtained to assess luteal function, according to a previously reported [21] method of evaluation. Serum hormones were quantified on the day of HCG administration and the same day as endometrial sampling. All samples were obtained between 8:00 a.m. and 10:00 a.m., and the clinical data for the four groups were analysed.

All patients signed an informed consent before receiving IVF treatment and biopsy, and this study was approved by the Ethics Committee of the Hospital.

\section{Endometrial samples}

Timed endometrial biopsies were taken from the uterine fundus using the Pipelle biopsy device (Cooper Surgical, USA). Endometrial samples were divided into two parts: the first one was fixed in $10 \%$ formalin and embedded in paraffin for immunohistochemical analysis of OPN and integrin $\alpha v \beta 3$ expression and histological dating, according to Noyes criteria [22]. The second portion was immediately snap-frozen in liquid nitrogen and used for real time quantitative polymerase chain reaction (RT-QPCR).

\section{Endometrial dating}

For endometrial dating, 5 - $\mu \mathrm{m}$ sections were stained with haematoxylin and eosin and evaluated according to the histopathological criteria of Noyes et al. [22]. All endometrial samples were evaluated by the experienced pathologist (H.Y.) who was blinded with regard to the ovulatory day and study group. An out-ofphase biopsy was defined as a lag of $\geq 3$ days between the chronological and histological day [23,24].

\section{Immunohistochemical analysis}

Immunohistochemistry for both OPN and integrin $\alpha v \beta 3$ were performed on 5 - $\mu \mathrm{m}$ sections of formalin-fixed, paraffin-embedded endometrial biopsies, using the EnVision ${ }^{\text {TM }}$ FLEX + system (Dako Co., Denmark). Mouse monoclonal anti-OPN (Akm2A1, dilution 1:100; Santa Cruz, CA, USA) and anti-integrin $\alpha v \beta 3$ (23C6, dilution 1:40; Santa Cruz, CA, USA) antibodies were applied. Paraffin sections were deparaffinised and rehydrated in xylene and graded alcohols, followed by heat-induced epitope retrieval (High PH). Endogenous peroxidase activity was blocked by incubating slides in 3\% hydrogen peroxide for 10 minutes at room temperature. The slides were then incubated with the primary antibodies for 60 minutes, followed by incubation with the secondary antibody from the EnVision ${ }^{\mathrm{TM}}$ FLEX + kit (Dako NenmarkA/S, Glostrup, Denmark) for 30 minutes. The reaction product was visualised with the prepared liquid diaminobenzidine substrate chromogen solution for 5 minutes; slides were then washed in distilled water, counterstained with haematoxylin, washed, dehydrated, and mounted. As previously reported [9], in every case a negative control was performed by omission of incubation with the specific primary antibody.

Immunostaining results were scored semi-quantitatively in each section. The staining intensity and positive percentage were evaluated, and the mean values were obtained. A staining score was calculated over 5 high-power fields using the following equation: HSCORE $=\Sigma \mathrm{P}_{i}(i+1)$, where $i$ was the intensity of staining with a value of 1,2 , or 3 (weak, moderate, or strong, respectively), and $\mathrm{P}_{i}$ was the percentage of stained luminal and glandular epithelial cells for each intensity, ranging from 0-100\% [25-27]. Previous reports have demonstrated low intra-observer $(r=0.983$; $\mathrm{p}<0.0001)$ and inter-observer $(\mathrm{r}=0.994 ; \mathrm{p}<0.0001)$ differences for HSCORE in uterine tissues using this technique [25]. Endometrial samples were considered to express OPN and/or integrin $\alpha v \beta 3$ when these glycoproteins were detected with any intensity in both the endometrial glands and luminal surface epithelium $[17,24,28]$.

\section{Real-time quantitative polymerase chain reaction}

Total RNA was extracted from endometrial tissues with TRIzol reagent (Sigma, USA) according to the manufacturer's instructions. The concentration and quality of RNA were determined using ultraviolet spectrophotometry at $260 \mathrm{~nm}$ and $280 \mathrm{~nm}$. Equal amounts of total RNA ( $2 \mu \mathrm{g})$ were reverse transcribed using the Superscript First Strand Synthesis System for RT-PCR (Invitrogen, Carlsbad, CA), and the resulting first-strand CDNA was diluted and used as a template in the RT-QPCR analysis. All measurements were performed in triplicate. The mRNA levels of OPN, $\beta 3$ integrin, and GAPDH (internal control to normalise for variances in input cDNA) were measured. The following gene-specific primers and probes were designed with the Oligo Primer Analysis 4.0 software, and the specificity of each primer was determined using the NCBI BLAST module (http://www.ncbi.nlm.nih.gov/ BLAST/). The primer sequences were as following: OPN sense (5'-CTAAGAAGTTTCGCAGACC-3'), OPN antisense (5'-CATTCAA CTCCTCGCTTT-3'); $\beta 3$ integrin sense (5'-TGCCGTGACGAGATTGAG-3'), $\beta 3$ integrin antisense (5'-GAGCAGGACCACCAGGAT-3'); and GAPDH sense (5'-ATCATCAGCAATGCCTCC-3'), GAPDH antisense (5'-CATCACGCCACAGTTTCC-3'). Detection of expression was performed with SYBR Green (FS Universal SYBR Green Master; Roche, Switzerland) and an ABI PRISM 7300 Real Time PCR instrument (Applied Biosystems, USA) using the relative standard curve method. For sample analysis, the threshold was set based on the exponential phase of products, and the $2^{-\Delta \Delta C T}$ method was performed to analyse the data as previously described [29]. The expression level of each gene was normalised to GAPDH mRNA and expressed as the n-fold difference relative to the control.

\section{Hormone assay}

Hormones were measured using commercially available kits. P and $\mathrm{E}_{2}$ levels in serum were measured using a competitive chemiluminescent assay (Access Immunoassay System, UniCel DXI 800; Beckman Coulter, USA). The sensitivity was $20 \mathrm{pg} / \mathrm{ml}$ for $\mathrm{E}_{2}$ and $0.10 \mathrm{ng} / \mathrm{ml}$ for $\mathrm{P}$, and the inter-assay coefficients of variation for $\mathrm{E}_{2}$ and $\mathrm{P}$ were $12 \%$ and $6.1 \%$, respectively.

\section{Statistical analysis}

Values were expressed as mean \pm standard error of the mean. The $\mathrm{X}^{2}$ test and Kruskal-Wallis test were used to analyze categroriacal data and continuous variables, respectively. The correlation between OPN and integrin $\alpha v \beta 3$ expression was evaluated using the Spearman rank correlation coefficient test. Statistical analyses were performed with the Statistical Package for Social Sciences version 11.5 (SPSS, Chicago, IL, USA). A p-value < 0.05 was considered to be statistically significant. 


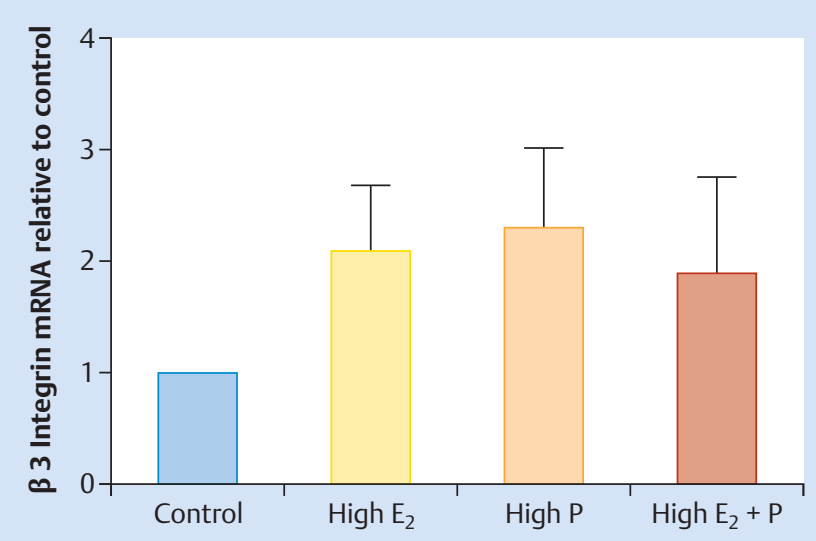

Fig. 1 Expression of $\beta 3$ integrin in the endometrial tissue during implantation window. The RT-QPCR analysis of $\beta 3$ integrin mRNA expression in endometrium of the four groups reveals an increase in transcript level during the implantation window in patients with high $E_{2}$, high $P$, and both high $E_{2}$ and high $P$.

\section{Results}

$\nabla$

\section{Characteristics of the enrolled volunteers}

The mean age of the women in the high E2, high P, high E2 and P, and control groups were $30.27 \pm 1.25,28.91 \pm 1.11,28.55 \pm 1.28$, and $29.45 \pm 1.18$ years (mean \pm standard error of the mean), respectively. All cycles included in the present study were ovulatory, according to oocyte retrieval or ultrasonographic criteria and mid-luteal serum P concentration $>10 \mathrm{mg} / \mathrm{ml}$. Accordingly, the endometrial specimens were noted to be clearly progestational fundal sample in all instances.

\section{The serum levels of $E_{2}$ and $P$}

Serum hormone concentrations are presented in 0 Table 1. As expected, $E_{2}$ and $P$ serum concentrations were significantly higher in cycles treated with ovarian stimulation than in control during the implantation window. The $\mathrm{E}_{2}$ concentration in the control group was much lower than that of the other three groups $(\mathrm{p}<0.05)$, but there was no difference in $E_{2}$ concentration among the high $E_{2}$, high $P$, and high $E_{2}$ and $P$ groups. However, the $P$ level did not reach statistical significance among the four groups during the implantation window ( $\bullet$ Table 1 ).

The expression level of $\beta 3$ integrin and the immunohistochemical analysis of integrin $\alpha v \beta 3$

Compared to the control group, the expression level of $\beta 3$ integrin mRNA in endometrial tissues was up-regulated during the implantation window in patients with high $\mathrm{E}_{2}$, high $\mathrm{P}$, and both

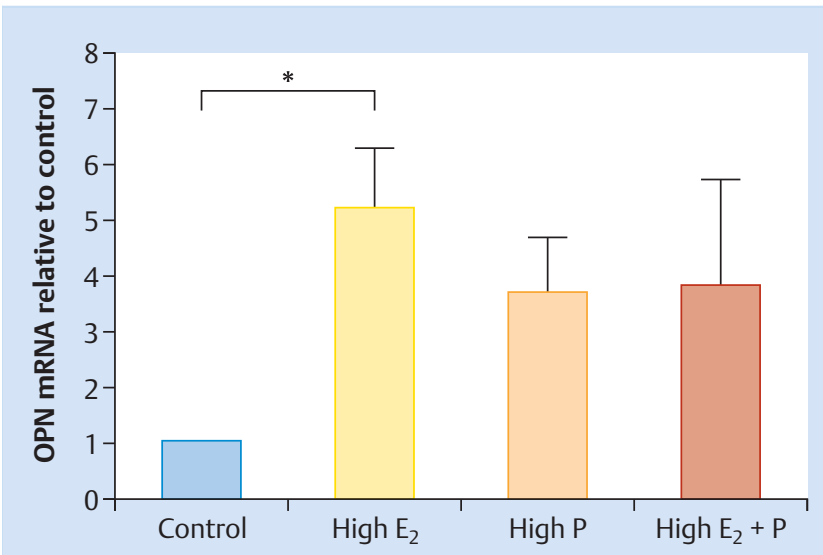

Fig. 2 Expression of OPN in the endometrial tissue during implantation window. The RT-QPCR analysis of OPN mRNA expression in endometrium of the four groups reveals a marked increase in transcript level during the implantation window in patients with high $P$, and both high $E_{2}$ and high $P$, especially in group high $E_{2}$.

high $E_{2}$ and $P(\bullet$ Fig. 1). Immunohistochemical analysis revealed that integrin $\alpha v \beta 3$ was mainly expressed on the membrane of glandular epithelial cells, and the staining was scattered and weakly positive ( Fig. 3). There were no significant differences with regard to mRNA $\beta 3$ integrin expression or $\beta 3$ integrin protein expression and intensity among the four groups ( $\square$ Table 2 ).

\section{The mRNA level of OPN}

The RT-QPCR analysis of OPN mRNA was performed using the same samples as those used for the $\beta 3$ integrin analysis (๑ Fig. 2). We indeed demonstrated a marked increase in OPN expression during the implantation window in the high $\mathrm{E}_{2}$, high $\mathrm{P}$, and high $E_{2}$ and $P$ groups, especially in the high $E_{2}$ group $(\mathrm{p}<0.05)$; however, there was no significant difference in OPN level among the high $\mathrm{E}_{2}$, high $\mathrm{P}$ and high $\mathrm{E}_{2}$ and $\mathrm{P}$ groups.

Up-regulation of OPN expression was confirmed by immunohistochemistry ( Fig.3). OPN staining was mostly moderate to strong in all patients, concentrated in the cytoplasm, and confined to the glandular and luminal epithelial compartments. Although OPN expression was higher in the high $\mathrm{E}_{2}$ group, no significant difference was found in OPN level among the control, high $E_{2}$, high $P$, and high $E_{2}$ and $P$ groups (all $p>0.05$, ๑ Table 2).

\section{Correlation between integrin $\alpha v \beta 3$ and OPN during the implantation window biopsies}

- Table 2 summarises the data related to endometrial histology and OPN and integrin $\alpha \mathrm{v} \beta 3$ expression or co-expression during the implantation window biopsies carried out in the control, high

Table 1 Serum hormone concentrations on the HCG day and the biopsy day in four groups.

\begin{tabular}{|c|c|c|c|c|}
\hline \multirow[t]{2}{*}{ Group } & \multicolumn{2}{|l|}{ HCG day } & \multicolumn{2}{|l|}{ Biopsy day } \\
\hline & Estradiol (pg/ml) & Progesterone (ng/ml) & Estradiol (pg/ml) & Progesterone (ng/ml) \\
\hline Group control & & & $190.28 \pm 18.11^{\mathrm{f}, \mathrm{g}, \mathrm{h}}$ & $18.13 \pm 1.51$ \\
\hline Group high $E_{2}$ & $6210.81 \pm 383.24^{a, b}$ & $0.87 \pm 0.07^{d}$ & $1563.55 \pm 334.57^{f}$ & $32.69 \pm 8.46$ \\
\hline Group high P & $3972.19 \pm 313.36^{a, c}$ & $2.8 \pm 0.37^{\mathrm{d}, \mathrm{e}}$ & $1569.45 \pm 385.65^{9}$ & $31.34 \pm 6.14$ \\
\hline Group both high $E_{2}+P$ & $7432.27 \pm 252.07^{b, c}$ & $1.63 \pm 0.12^{\mathrm{e}}$ & $1830.27 \pm 489.45^{h}$ & $30.41 \pm 4.62$ \\
\hline
\end{tabular}

Values are expressed as mean \pm SEM.

${ }^{a-h}$ Figures with common superscripts are significantly different $(p<0.05)$. 


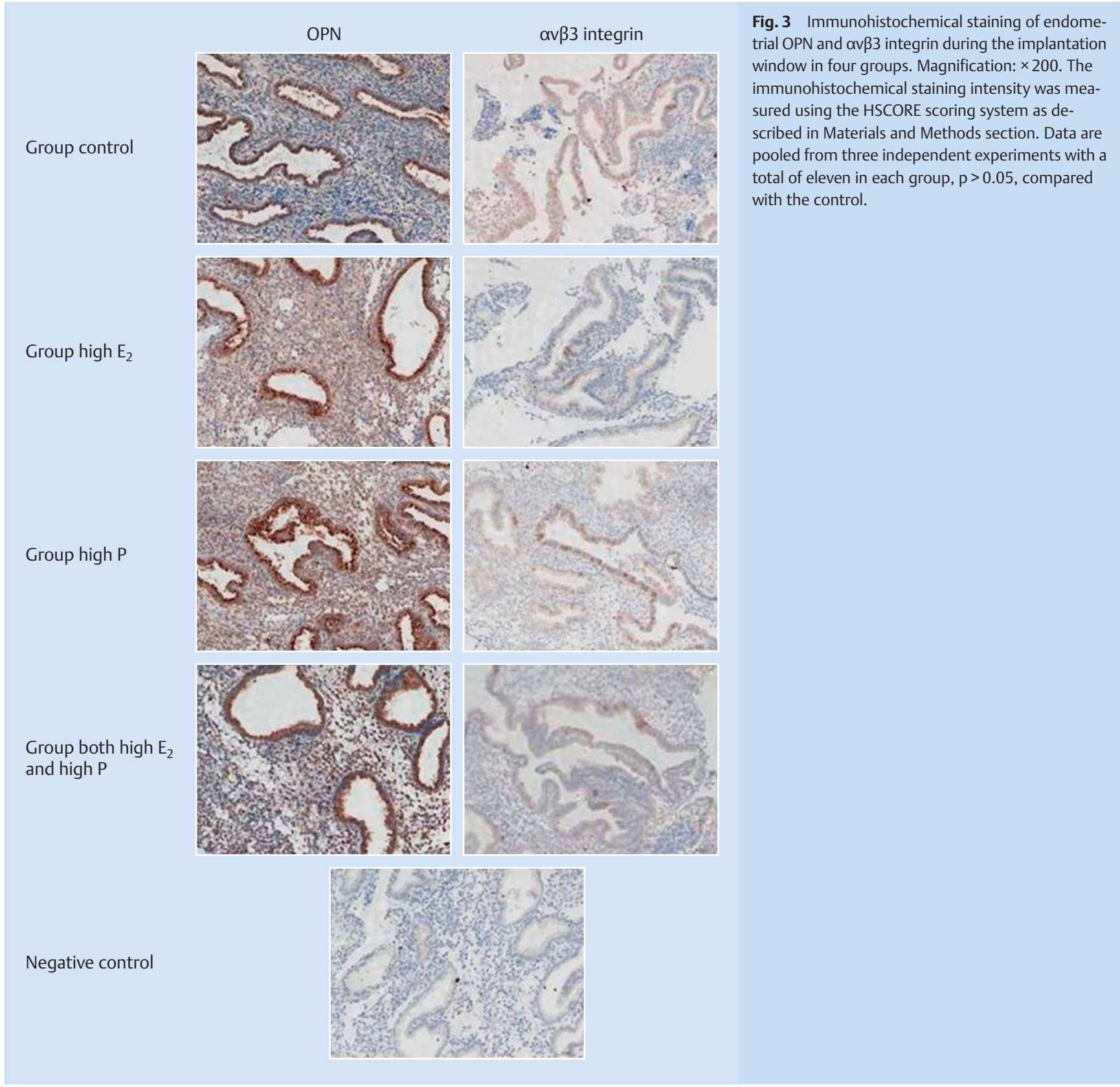

Table 2 Endometrial biopsy and epithelial OPN and $\alpha \mathrm{v} \beta 3$ integrin expression and their co-expression in the four groups studied during the implantation window.

\begin{tabular}{|c|c|c|c|c|c|}
\hline Parameter & $\begin{array}{l}\text { Group control } \\
(n=11)\end{array}$ & $\begin{array}{l}\text { Group high } E_{2} \\
(n=11)\end{array}$ & $\begin{array}{l}\text { Group high P } \\
(n=11)\end{array}$ & $\begin{array}{l}\text { Group both high } \\
E_{2}+P(n=11)\end{array}$ & $\mathrm{P}$ value \\
\hline \multicolumn{6}{|l|}{ Endometrial biopsy } \\
\hline Chronological dating & $7.09 \pm 0.09$ & $7.27 \pm 0.14$ & $7.18 \pm 0.12$ & $7.27 \pm 0.14$ & NS \\
\hline In-phase endometrial & $10(90.9)$ & $8(72.7)$ & $10(90.9)$ & $9(81.8)$ & NS \\
\hline \multicolumn{6}{|l|}{ OPN expression } \\
\hline Positive samples & $10(90.9)$ & $11(100)$ & $11(100)$ & $11(100)$ & NS \\
\hline HSCORE & $1.18 \pm 0.26$ & $1.59 \pm 0.26$ & $1.41 \pm 0.32$ & $1.10 \pm 0.14$ & NS \\
\hline \multicolumn{6}{|c|}{$\alpha v \beta 3$ integrin expression } \\
\hline Positive samples & $4(36.36)$ & $3(27.27)$ & $6(54.54)$ & $2(18.18)$ & NS \\
\hline HSCORE & $0.54 \pm 0.23$ & $0.27 \pm 0.18$ & $0.45 \pm 0.18$ & $0.29 \pm 0.19$ & NS \\
\hline \multicolumn{6}{|c|}{ OPN/ $\alpha$ $\beta 3$ co-expression } \\
\hline OPN $(-) / \alpha v \beta 3(-)$ & $1(9.09)$ & 0 & 0 & 0 & NS \\
\hline OPN $(+) / \alpha v \beta 3(-)$ & $6(54.54)$ & $8(72.72)$ & $5(45.45)$ & $9(81.81)$ & NS \\
\hline OPN (-)/ $\alpha v \beta 3(+)$ & 0 & 0 & 0 & 0 & NS \\
\hline OPN $(+) / \alpha v \beta 3(+)$ & $4(36.36)$ & $3(27.27)$ & $6(54.54)$ & $2(18.18)$ & NS \\
\hline
\end{tabular}

Values are expressed as mean \pm SEM or $\mathrm{n}(\%)$. 

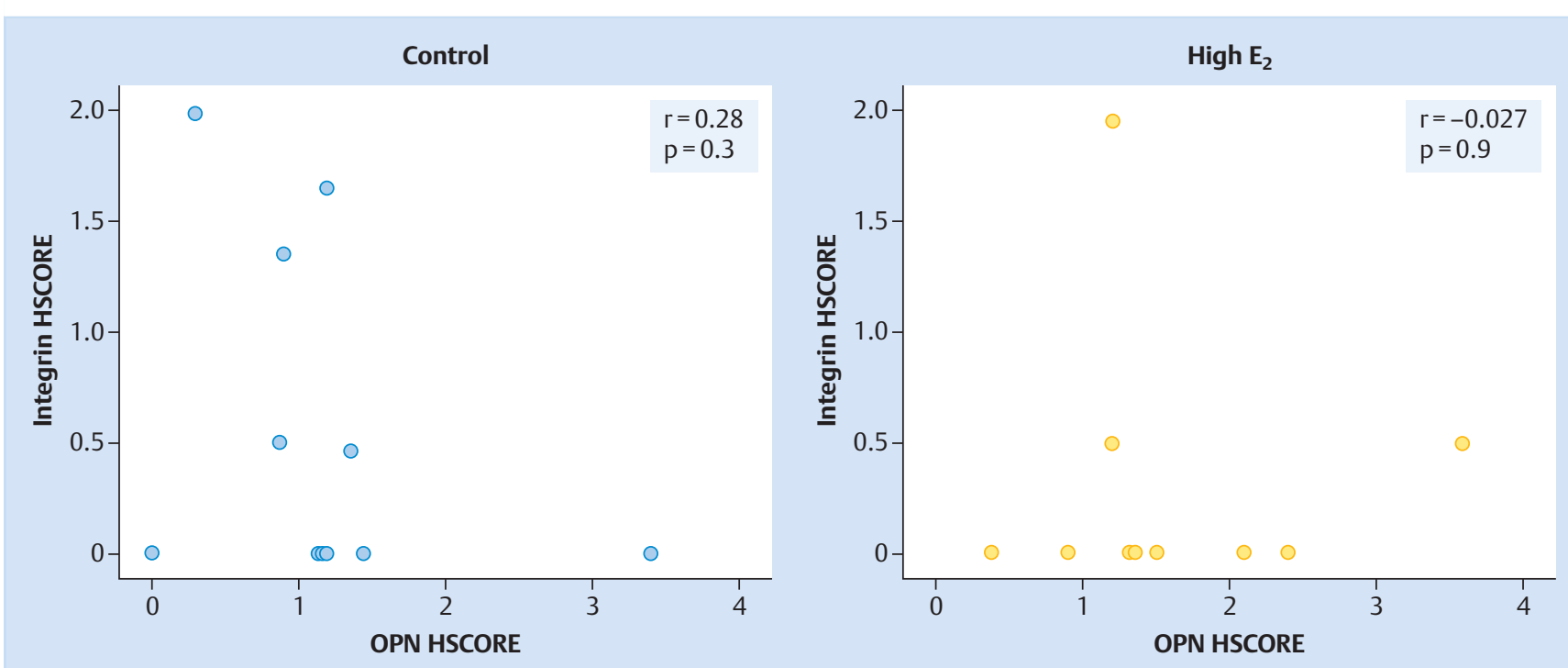

High P

High $E_{2}$ and high $P$
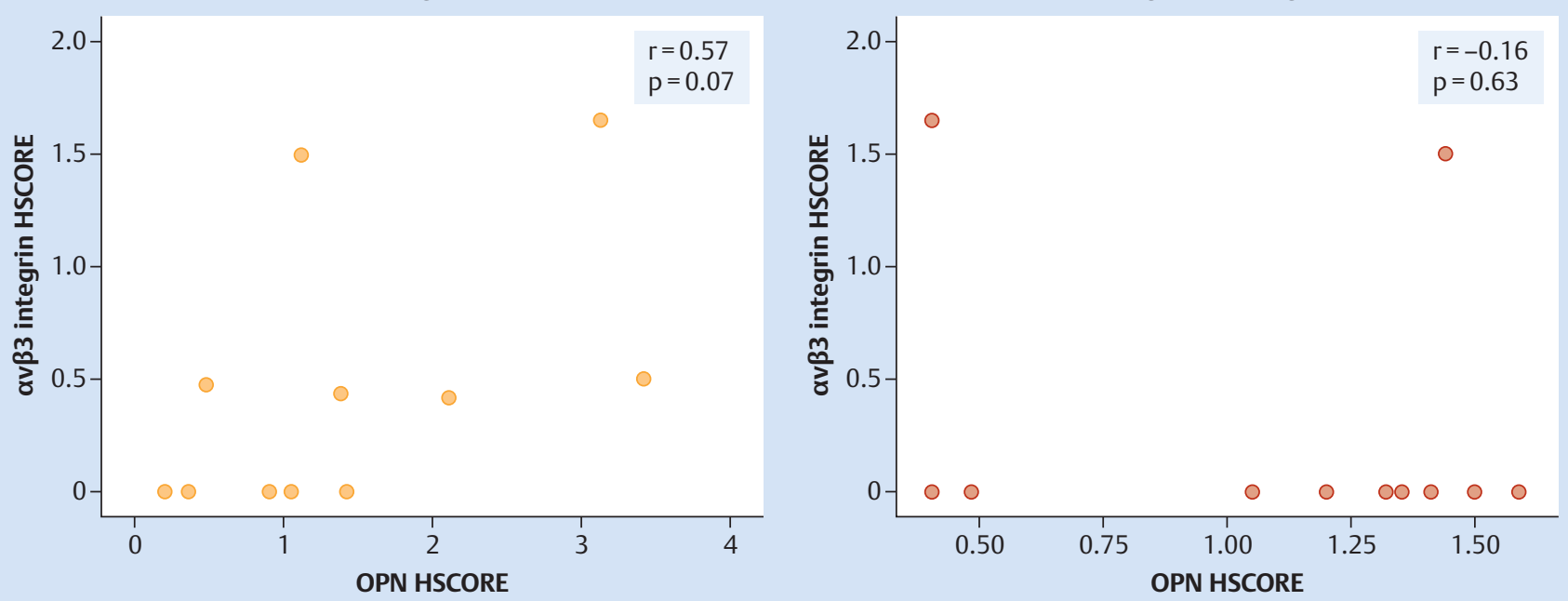

Fig. 4 Correlation between staining intensity for OPN and $\alpha v \beta 3$ integrin expression during the implantation window in endometrial biopsies in patients of high $E_{2}$, high $P$, both high $E_{2}$ and high $P$, and control group.

$\mathrm{E}_{2}$, high $\mathrm{P}$, and high $\mathrm{E}_{2}$ and $\mathrm{P}$ groups. No statistically significant differences were found among the four groups with respect to histology or, expression of endometrial markers during the implantation window. The simultaneous presence of both markers was observed in only $34.1 \%$ (15/44) of mid-luteal biopsies, with no differences among the four groups. There was no significant correlation between integrin $\alpha v \beta 3$ and OPN staining intensity during the implantation window biopsies in any of the study groups (๑ Fig. 4).

\section{Discussion}

$\nabla$

Successful implantation of embryos is an important physiologic event in the establishment of pregnancy [30]. During IVF cycle, high serum P concentrations on the day of HCG administration could have an adverse effect on endometrial condition, as could the combination of high $\mathrm{P}, \mathrm{E}_{2}$ level, a pattern observed through our clinical research [5]. However, the question remains as to which factors affect endometrial receptivity of patients with high
$\mathrm{P}$ and/or $\mathrm{E}_{2}$. In recent years, many studies have investigated potential causes of reduction in endometrial receptivity [31]. Several adhesion molecules considered essential for uterine competence during implantation have been proposed as markers of endometrial receptivity [32-34]. In particular, integrin $\alpha v \beta 3$ and its ligand OPN have been intensively studied in reproductive medicine $[18,35,36]$; assessment of these two glycoproteins has been proposed as a novel approach to determine uterine receptivity for various causes of infertility [21]. However, there are very few published studies investigating the cellular mechanism of action of high serum $P$ and $E_{2}$ in IVF cycle. In the present study, we employed OPN and integrin $\alpha \mathrm{v} \beta 3$ as markers of emdometrial receptivity. To our knowledge, there have been no prior studies on the effect of elevated serum $P$ and/or $E_{2}$ levels on the expression of OPN and integrin $\alpha v \beta 3$ during the implantation window.

It is surprising that our findings demonstrated that there was no significant difference among the four study groups in the expression of OPN and integrin $\alpha v \beta 3$ during the implantation window. Furthermore, there was no significant correlation between integ- 
rin $\alpha v \beta 3$ and OPN staining intensity during the implantation window in any of the groups studied.

Nevertheless, we confirmed the temporal and spatial expression of these two major markers of endometrial receptivity. Both OPN and integrin $\alpha v \beta 3$ demonstrate an abrupt onset of staining in the luminal and glandular epithelium from the early to mid-secretory phase onward [18]. Maximal expressions of both OPN and integrin $\alpha v \beta 3$ during the mid to late secretory phase in human endometrial epithelial cells and secretion of OPN into the uterine cavity suggest both factors play a role in the regulation of endometrial function and embryo implantation $[8,9]$. Previous studies $[8,37]$ reported that OPN and integrin $\alpha v \beta 3$ were differentially regulated by ovarian steroids along with epidermal growth factor (EGF) and heparin-binding EGF (HB-EGF). They demonstrated that E2 and E2 in combination with P reduced the expression of $\beta 3$ integrin. Inhibition of E2 by the antagonist ICI 182780 increased the relative expression of $\beta 3$, whereas the antiprogestin Ru-486 had little effect. In addition, EGF and HB-EGF dramatically increased $\beta 3$ subunit expression. On the other hand, expression of OPN was modulated by P and dramatically increased with both E2 and P, whereas E2 alone also appeared to antagonise its expression. Ru-486 reduced the stimulatory effect of $\mathrm{P}$ on OPN, whereas HB-EGF had little if any effect on its expression [8].

We found no significant difference in levels of $\beta 3$ mRNA or integrin $\alpha v \beta 3$ expression during the receptive phase when comparing the high $E_{2}$, high $P$, high $E_{2}$ and $P$, and control groups. Research has shown that there was no significant difference in $\alpha v \beta 3$, $\alpha 4 \beta 1$, and $\alpha 1 \beta 1$ integrin expression between patients undergoing IVF or intracytoplasmic sperm injection (ICSI) and the control group [38]. These data add to the increasing uncertainty about the clinical value of assessing the endometrium with only integrins. Thomas et al. [39] studied the endometrial expression of these three integrins in 66 women undergoing ICSI treatment (at LH + 7-9 days) and the subsequent success rate. The results demonstrated that there was significantly increased expression of integrin $\alpha v \beta 3$ in the luminal epithelium of patients for whom treatment was successful compared to patients for whom treatment was unsuccessful. However, treatment was successful in some patients with negative expression. They concluded that the clinical value of assessing the endometrium before treatment has certain drawbacks, and the expression of $\alpha 1, \alpha 4$, and integrin $\alpha v \beta 3 \mathrm{~s}$ appears to have no prognostic value with regard to subsequent IVF treatment.

Using the same samples, we confirmed a significant up-regulation of OPN mRNA during the implantation window in the high $E_{2}$, high P, and high $E_{2}$ and P groups. OPN has been found to be consistently up-regulated in the endometrium during the window of implantation in different studies of the transcriptome $[18,40-42]$. In a study by Li et al. [41], a microRNA array and microarray were performed to evaluate the endometrial receptivity in 12 patients with high serum P level and 7 fertile women with normal P on the day of HCG administration. Spp1 (osteopontin precursor) and ang (angiogenin precursor) were up-regulated genes, and RT-PCR verified the array results. Immunohistochemical analysis indicated that elevated OPN and decreased vascular endothelial growth factor in patients with high $P$ levels on the day of HCG administration had poor pregnancy rate. However, in the present study, no significant difference in endometrial OPN immunoreactivity was observed among patients with high $\mathrm{P}$, high $E_{2}$, or high $E_{2}$ and $P$, compared with the control group.

Our immunohistochemical analysis of OPN and its receptor integrin $\alpha v \beta 3$ did not show different expression of these two markers, either alone or in combination, among the specimens of the high $P$, high $E_{2}$, high $E_{2}$ and $P$, and control groups. Discrepancies between different studies may be explained by the following facts: First, discordant results were often obtained in infertile patients because of the heterogeneity of patients included in the same study group. To avoid this circumstance, the inclusion of patients in the current study was restricted to patients unable to conceive because of tubal obstruction or male infertility. Cases with endometriosis, hydrosalpinges, PCOS and unexplained infertility were excluded.

Second, the clinical value of assessing the endometrium before treatment has certain drawbacks [39]. Endometrial samples obtained during the implantation window in spontaneous cycle have been included in some investigations $[18,38,39]$; however, we and others demonstrated changes in the endometrial expression of OPN and integrin $\alpha v \beta 3$ during the implantation window in the same IVF cycle [17,41].

Third, the analysis of mRNA or protein expression could produce discrepant results because not all mRNA molecules could be translated into protein [43]. Finally, the simultaneous presence of both OPN and integrin $\alpha \mathrm{v} \beta 3$ was observed in only $34.1 \%$ (15/ 44) of cases during the implantation window in our study. In studies by Cacals et al. [21,44], two biopsies were performed during a single menstrual cycle in each subject. The simultaneous presence of both OPN and integrin $\alpha v \beta 3$ was only observed in $33.33-41.18 \%$ of cases in the mid-luteal phase, but $98-100 \%$ of cases in the late-luteal phase. Nevertheless, previous research confirmed that there was dynamic expression of several integrins in the human endometrium [28]. It was found that integrin $\alpha v \beta 3$ expression was closely correlated with histological maturation of the endometrium, with expression occurring primarily at postovulatory days $6-7$, whereas OPN expression occurred primarily at post-ovulatory days $4-5$. Both markers were expressed by all endometria dated post-ovulatory day $\geq 8$. The intensity of their expression also increased from mid-luteal to late post-ovulatory days. These changes in OPN and integrin $\alpha v \beta 3$ expression occurred irrespective of endometria being in-phase or out-of-phase [21]. In our study, only one biopsy was performed at 7-8 days after oocyte retrieval or ovulation. The staining of integrin $\alpha v \beta 3$ was scattered and weakly positive, but the staining of OPN was mostly moderate to strong, with positive expression in all patients during the implantation window, consistent with previous studies.

While we observed that serum P level at the time of biopsy was significantly increased in stimulated patients, there was no difference among the four groups. Ovarian stimulation is known to advance endometrial maturation, and P may hasten the closure of the implantation window [45]. A recent study by Papanikolaou et al. [46] showed that increased P level on the day of HCG administration impaired pregnancy outcome in day-3 single ETs, whilst it had no effect on day-5 single-blastocyst transfer. It was proposed that high follicular $\mathrm{P}$ concentration greatly advances the endometrium; therefore, the placement of a day-3 embryo in an asynchronous endometrium (earlier than a natural pregnancy) resulted in failure to establish an embryo endometrium crossdialogue and a failed implantation. The negative impact of premature luteinization on pregnancy rate with blastocyst transfer suggested that the endometrium has already significantly recovered from the violation induced from the supra-physiological steroid concentration on the fifth luteal day. Thus, a proposed strategy for cases with P elevation on the day of HCG administration is the selection for ET on day 5. Our present study showed 
that endometrial OPN and integrin $\alpha \mathrm{v} \beta 3$ expression or co-expression during the window of implantation were not impaired in patients with elevated $\mathrm{P}$ and/or high $\mathrm{E}_{2}$ levels. However, whether these results indicate that normal endometrial receptivity has also recovered from the violation induced from the supraphysiological steroid concentration on the fifth luteal day, which needs further exploration.

According to our results, if OPN and integrin $\alpha \mathrm{v} \beta 3$ are proven to be accurate markers of uterine receptivity, it may be concluded that there is no endometrial impairment in patients with high $\mathrm{P}$ and/or $E_{2}$. However, some investigations have reported uncertainty about the value of OPN and integrins in assessing endometrial receptivity in the clinical setting $[17,21,28,38,44]$. Furthermore, a limitation of this study was the relatively small number of study participants, and these results should be confirmed in a large population. The HSCORE values may become more significant if a larger study population is used; nevertheless, the finding of no difference in staining among patients with high $\mathrm{P}$ and/or $\mathrm{E}_{2}$ indicated that elevated hormone levels on the day of HCG administration has no impact on uterine receptivity during the implantation window.

In conclusion, the results of the present study show that OPN and integrin $\alpha v \beta 3$ expression or co-expression during the window of implantation are not impaired in patients with elevated $\mathrm{P}$ and/or $\mathrm{E}_{2}$ on the day of HCG administration.

\section{Conflict of Interest}

$\nabla$

The author(s) declared no conflicts of interest with respect to the authorship and/or publication of this article.

\section{Affiliations}

${ }^{1}$ Department of Reproduction and Genetics, Reproductive Medical Centre, The Affiliated Hospital of Kunming University of Science and Technology, The First People's Hospital of Yunnan Province, Kunming, People’s Republic of China

2 Department of Pathology, The First People's Hospital of Yunnan Province, Kunming, People's Republic of China

${ }^{3}$ Institute of Molecular and Clinical Medicine, Kunming Medical University, Chengong New District, Kunming, People's Republic of China

${ }^{4}$ Department of Obstetrics and Gynecology, Reproductive Medical Centre, Peking University Third Hospital, Haidian District, Beijing, People's Republic of China

\section{References}

1 Achache $H$, Revel A. Endometrial receptivity markers, the journey to successful embryo implantation. Hum Reprod Update 2006; 12: 731746

2 Ubaldi F, Camus M, Smitz J et al. Premature luteinization in in vitro fertilization cycles using gonadotropin-releasing hormone agonist (GnRH-a) and recombinant follicle-stimulating hormone (FSH) and GnRH-a and urinary FSH. Fertil Steril 1996; 66: 275-280

3 Bosch E, Valencia I, Escudero E et al. Premature luteinization during gonadotropin-releasing hormone antagonist cycles and its relationship with in vitro fertilization outcome. Fertil Steril 2003; 80: 1444-1449

4 Arslan M, Bocca S, Arslan E et al. Cumulative exposure to high estradiol levels during the follicular phase of IVF cycles negatively affects implantation. J Assist Reprod Genet 2007; 24: 111-117

$5 \mathrm{Wu}$ Z, Li R, Ma YP et al. Effect of HCG-day serum progesterone and oestradiol concentrations on pregnancy outcomes in GnRH agonist cycles. Reprod Biomed Online 2012; 24: 511-520

6 Castelbaum AJ, Wheeler J, Coutifaris C et al. Timing of the endometrial biopsy may be critical for the accurate diagnosis of luteal phase deficiency. Fertil Steril 1994; 61: 443-447

7 Borthwick JM, Charnock-Jones DS, Tom BD et al. Determination of the transcript profile of human endometrium. Mol Hum Reprod 2003; 9: 19-33
8 Apparao KB, Murray MJ, Fritz MA et al. Osteopontin and its receptor alphavbeta(3) integrin are coexpressed in the human endometrium during the menstrual cycle but regulated differentially. J Clin Endocrinol Metab 2001; 86: 4991-5000

9 von Wolff M, Strowitzki T, Becker Vet al. Endometrial osteopontin, a ligand of beta3-integrin, is maximally expressed around the time of the "implantation window". Fertil Steril 2001; 76: 775-781

10 Lessey $B A$. Implantation defects in infertile women with endometriosis. Ann N Y Acad Sci 2002; 955: 265-280

11 Makker A, Singh MM. Endometrial receptivity: clinical assessment in relation to fertility, infertility, and antifertility. Med Res Rev 2006; 26 : 699-746

12 Strowitzki T, Germeyer A, Popovici R et al. The human endometrium as a fertility-determining factor. Hum Reprod Update 2006; 12: 617-630

13 Boroujerdnia MG, Nikbakht R. Beta3 integrin expression within uterine endometrium and its relationship with unexplained infertility. Pak J Biol Sci 2008; 11: 2495-2499

14 Ceydeli $N$, Kaleli S, Calay Z et al. Difference in alpha(v)beta3 integrin expression in endometrial stromal cell in subgroups of women with unexplained infertility. Eur J Obstet Gynecol Reprod Biol 2006; 126: 206211

15 Lessey BA, Castelbaum AJ, Sawin SW et al. Aberrant integrin expression in the endometrium of women with endometriosis. J Clin Endocrinol Metab 1994; 79: 643-649

16 Savaris RF, Pedrini JL, Flores $R$ et al. Expression of alpha 1 and beta 3 integrins subunits in the endometrium of patients with tubal phimosis or hydrosalpinx. Fertil Steril 2006; 85: 188-192

17 Casals G, Ordi J, Creus $M$ et al. Osteopontin and alphavbeta3 integrin as markers of endometrial receptivity: the effect of different hormone therapies. Reprod Biomed Online 2010; 21: 349-359

18 DuQuesnay R, Wright C, Aziz AA et al. Infertile women with isolated polycystic ovaries are deficient in endometrial expression of osteopontin but not alphavbeta3 integrin during the implantation window. Fertil Steril 2009; 91: 489-499

19 Peters AJ, Lloyd RP, Coulam CB. Prevalence of out-of-phase endometrial biopsy specimens. Am J Obstet Gynecol 1992; 166: 1738-1745

20 Shoupe D, Mishell DRJ, Lacarra $M$ et al. Correlation of endometrial maturation with four methods of estimating day of ovulation. Obstet Gynecol 1989; 73: 88-92

21 Casals G, Ordi J, Creus M et al. Osteopontin and alphavbeta3 integrin expression in the endometrium of infertile and fertile women. Reprod Biomed Online 2008; 16: 808-816

22 Noyes RW, Hertig AT, RockJ. Dating the endometrial biopsy. Am J Obstet Gynecol 1975; 122: 262-263

23 Creus $M$, Ordi J, Fábregues $F$ et al. alphavbeta3 integrin expression and pinopod formation in normal and out-of-phase endometria of fertile and infertile women. Hum Reprod 2002; 17: 2279-2286

24 Ordi J, Creus M, Ferrer B et al. Midluteal endometrial biopsy and alphavbeta3 integrin expression in the evaluation of the endometrium in infertility: implications for fecundity. Int J Gynecol Pathol 2002; 21: 231238

25 Budwit-Novotny DA, McCarty KS, Cox EB et al. Immunohistochemical analyses of estrogen receptor in endometrial adenocarcinoma using a monoclonal antibody. Cancer Res 1986; 46: 5419-5425

26 Lessey BA, Albelda S, Buck CA et al. Distribution of integrin cell adhesion molecules in endometrial cancer. Am J Pathol 1995; 146: 717-726

27 Ruan HC, Zhu XM, Luo Q et al. Ovarian stimulation with GnRH agonist, but not GnRH antagonist, partially restores the expression of endometrial integrin beta3 and leukaemia-inhibitory factor and improves uterine receptivity in mice. Hum Reprod 2006; 21: 2521-2529

28 Creus $M$, Balasch J, Ordi J et al. Integrin expression in normal and outof-phase endometria. Hum Reprod 1998; 13: 3460-3468

29 Livak KJ, Schmittgen TD. Analysis of relative gene expression data using real-time quantitative PCR and the 2(-Delta Delta C(T)) Method. Methods 2001; 25: 402-408

30 Salamonsen LA. Role of proteases in implantation. Rev Reprod 1999; 4: $11-22$

31 Nikas G, Develioglu OH, Toner JP et al. Endometrial pinopodes indicate a shift in the window of receptivity in IVF cycles. Hum Reprod 1999; 14: 787-792

32 Giudice LC. Potential biochemical markers of uterine receptivity. Hum Reprod 1999; 14 (Suppl. 2): 3-16

33 Lessey BA. Adhesion molecules and implantation. J Reprod Immunol 2002; 55: 101-112 
34 Lessey BA. Two pathways of progesterone action in the human endometrium: implications for implantation and contraception. Steroids 2003; 68: 809-815

35 Franchi A, Zaret J, Zhang $X$ et al. Expression of immunomodulatory genes, their protein products and specific ligands/receptors during the window of implantation in the human endometrium. Mol Hum Reprod 2008; 14: 413-421

36 Quenby S, Anim-Somuah M, Kalumbi C et al. Different types of recurrent miscarriage are associated with varying patterns of adhesion molecule expression in endometrium. Reprod Biomed Online 2007; 14: 224234

37 Somkuti SG, Yuan L, Fritz M et al. Epidermal growth factor and sex steroids dynamically regulate a marker of endometrial receptivity in Ishikawa cells. J Clin Endocrinol Metab 1997; 82: 2192-2197

38 Thomas K, Thomson AJ, Wood SJ et al. Endometrial integrin expression in women undergoing IVF and ICSI: a comparison of the two groups and fertile controls. Hum Reprod 2003; 18: 364-369

39 Thomas K, Thomson A, Wood S et al. Endometrial integrin expression in women undergoing in vitro fertilization and the association with subsequent treatment outcome. Fertil Steril 2003; 80: 502-507

40 Kao LC, Tulac S, Lobo S et al. Global gene profiling in human endometrium during the window of implantation. Endocrinology 2002; 143: $2119-2138$
$41 \mathrm{Li}$, Qiao J, Wang L et al. MicroRNA array and microarray evaluation of endometrial receptivity in patients with high serum progesterone levels on the day of hCG administration. Reprod Biol Endocrinol 2011; 9: 29

42 Riesewijk A, Martín J, van Os R et al. Gene expression profiling of human endometrial receptivity on days $\mathrm{LH}+2$ versus $\mathrm{LH}+7$ by microarray technology. Mol Hum Reprod 2003; 9: 253-264

43 Cho S, Ahn YS, Choi YS et al. Endometrial osteopontin mRNA expression and plasma osteopontin levels are increased in patients with endometriosis. Am J Reprod Immunol 2009; 61: 286-293

44 Casals G, Ordi J, Creus $M$ et al. Expression pattern of osteopontin and alphavbeta3 integrin during the implantation window in infertile patients with early stages of endometriosis. Hum Reprod 2012; 27: 805813

45 Hofmann GE, Bergh PA, Guzman I et al. Premature luteinization is not eliminated by pituitary desensitization with leuprolide acetate in women undergoing gonadotrophin stimulation who demonstrated premature luteinization in a prior gonadotrophin-only cycle. Hum Reprod 1993; 8: 695-698

46 Papanikolaou EG, Kolibianakis EM, Pozzobon C et al. Progesterone rise on the day of human chorionic gonadotropin administration impairs pregnancy outcome in day 3 single-embryo transfer, while has no effect on day 5 single blastocyst transfer. Fertil Steril 2009; 91: 949-952 